Anal ysi s of a novel I ami nated coi I using eddy currents for ac hi gh magnet i $c$ fi el d

\begin{tabular}{|l|l|}
\hline 著者 & $\begin{array}{l}\text { Bessho Kazuo, Yanada Sot oshi, Koot o M, } \\
\text { Hayashi gi shi M, Fur ut a M }\end{array}$ \\
\hline $\begin{array}{l}\text { j our nal or } \\
\text { publ i cat i on ti t l e }\end{array}$ & I EEE Transact i ons on Magget i cs \\
\hline vol une & 25 \\
\hline number & 4 \\
\hline page range & $2855-2858$ \\
\hline year & $1989-07-01$ \\
\hline URL & ht t p: //hdl . handl e. net /2297/48311 \\
\hline
\end{tabular}




\title{
ANALYSIS OF A NOVEL LAMINATED COIL USING EDDY CURRENTS FOR AC IIIGH MAGNETIC FIELD
}

\author{
K.Bessho SiYamada M.Kooto M.Hayash1g1sh1 M.Furut
}

Electrical Energy Conversion Laboratory

Faculty of Technology, Kanazawa University

Kodatsuno 2-40-20, Kanazawa, Japan

\section{ABSTRACT}

The paper describes the performance and analysis of eddy-current type laminated coll for ac high magnetlc fleld. It is difflcult to obtain an ac high magnetlc fleld by using an alr-gap coll because of eddy currents. For our device, pe can obtaln an ac hlgh magnetic pleld by means of the magnetlc shielding effect of eddy currents. Two kinds of a new type of coll are proposed in order to construct the apparatus easliy. The fleld distributions were analyzed by the two-dimensional finite element method.

\section{INTRODUCTION}

lntil now very fel papers on the ac hlgh magnetlc lleld generation were reported. It is difficult to generate an ac high magnetic field by the alr-gap coil because of eddy-current problems. On the other hand, we reported the AC HIgh Magnetic Fleld Generator by using the effect of the magnetic shleld of the conducting plate[1]-[3]. In the generator, the effect of the eddy currents acts as the main principle and the eddy currents generate an ac high magnetlc fleld.

In this paper, new colls for the ac generator are proposed in order to improve the construction and are analyzed by the finite element method.

\section{TTIE EDDY-CURRENT TYPE GENERATOR}

The concentration of the magnetic flux in the ac high magnetlc field generator is based on the magnetic plux shleld in the ac magnetic fleld. For concentrating the magnetic flux by using the magnetic plux shleld. it is necessary to set up a sllt in the radial direction as shown in Flg.1. The eddy currents flow around the hole due to the slit. Therefore, the magnetlc plux is shlelded in a copper plate, and the induction magnetic fleld whlch has the same direction as the applied magnetic fleld can be induced in the hole. The magnetlc flux density becomes hlgher.

In order to reallze the principle of the ac generation, we constructed the multllayer eddy-current type generator in Fig.2. The magnetizing coll and the

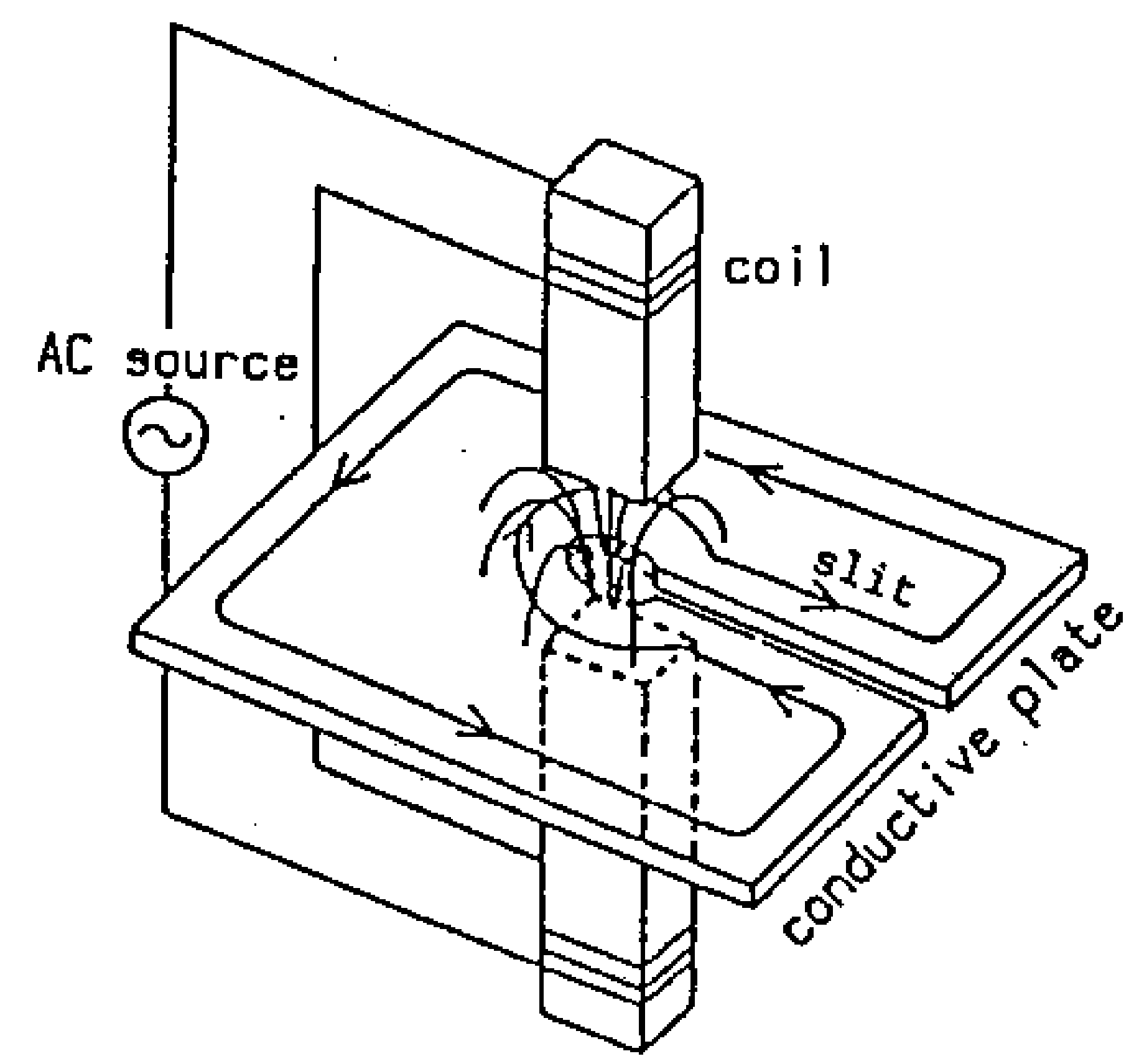

Fig.1 Concentration of a magnetic flux by eddy currents conductor for eddy currents are closely packed in Fig.2(a). The multilayer coll is assembled in the generator as shown in Fig.2(b). The shaded portlon of the apparatus is section of the coll and the poles. The yoke is added as part of the magnetic circult in the generator. Figure 3 shows the flux distribution obtalned by the two-dimensional finite element method. The characteristics of the multilayer eddycurrent type generator are shown as in Fig.4. The coll produces an ac flux density of $16 \mathrm{~T}$ at $60 \mathrm{~Hz}[3]$. Comparing with the plate-type conductor in Flg.1, these colls offer excellent performance characteristics. It is clear that the concentration effect can be improved considerably.

\section{STRUCTURE OF TIE LAMINATED TYPE COIL}

\section{Disc-type coil}

It is difficult to construct the Multilayer EddyCurrent Type coil because the conductor is solid copper. To improve the coll in construction, we propose two types of the laminated type coll. one of

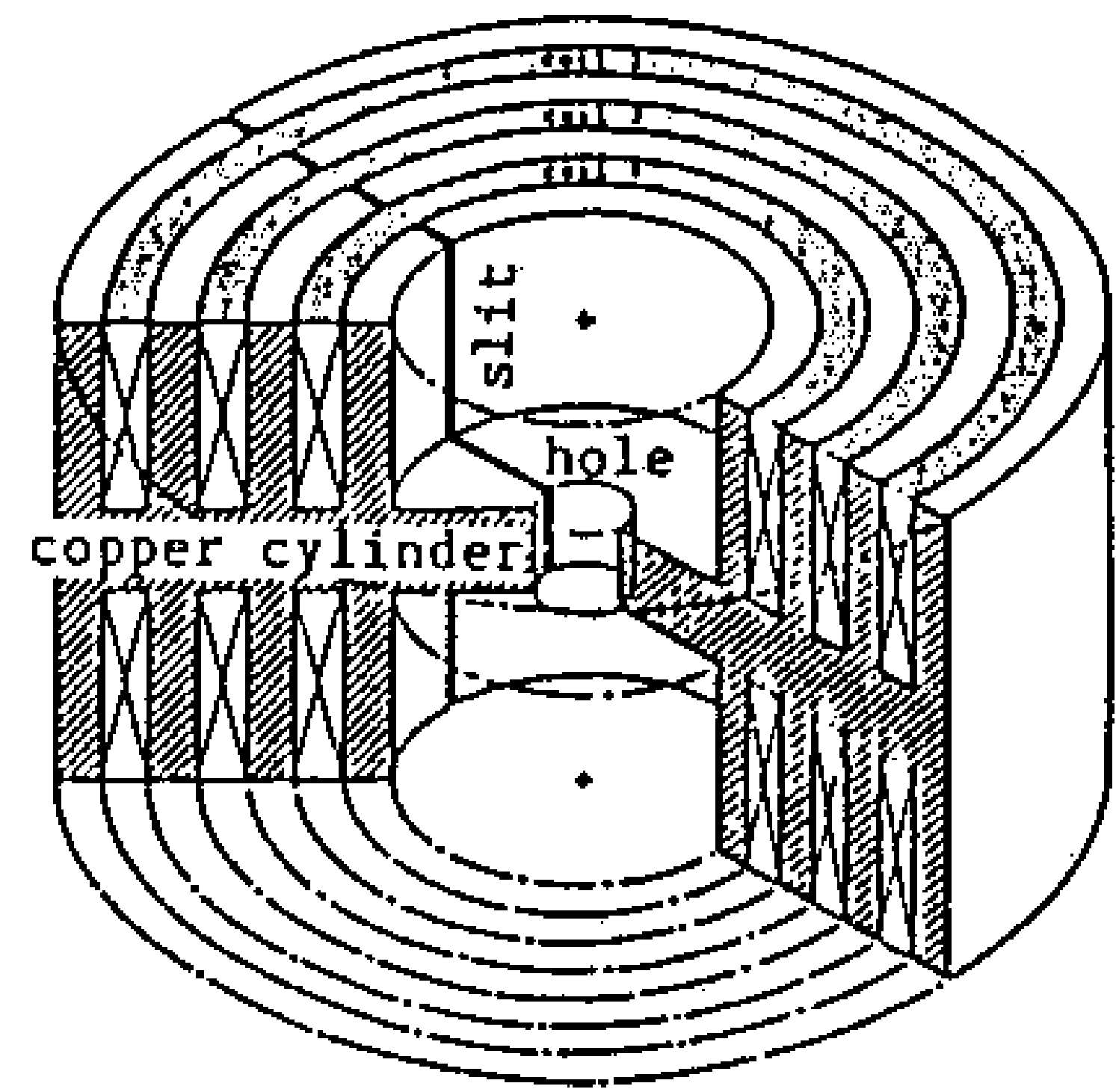

(a) Multllayer coll

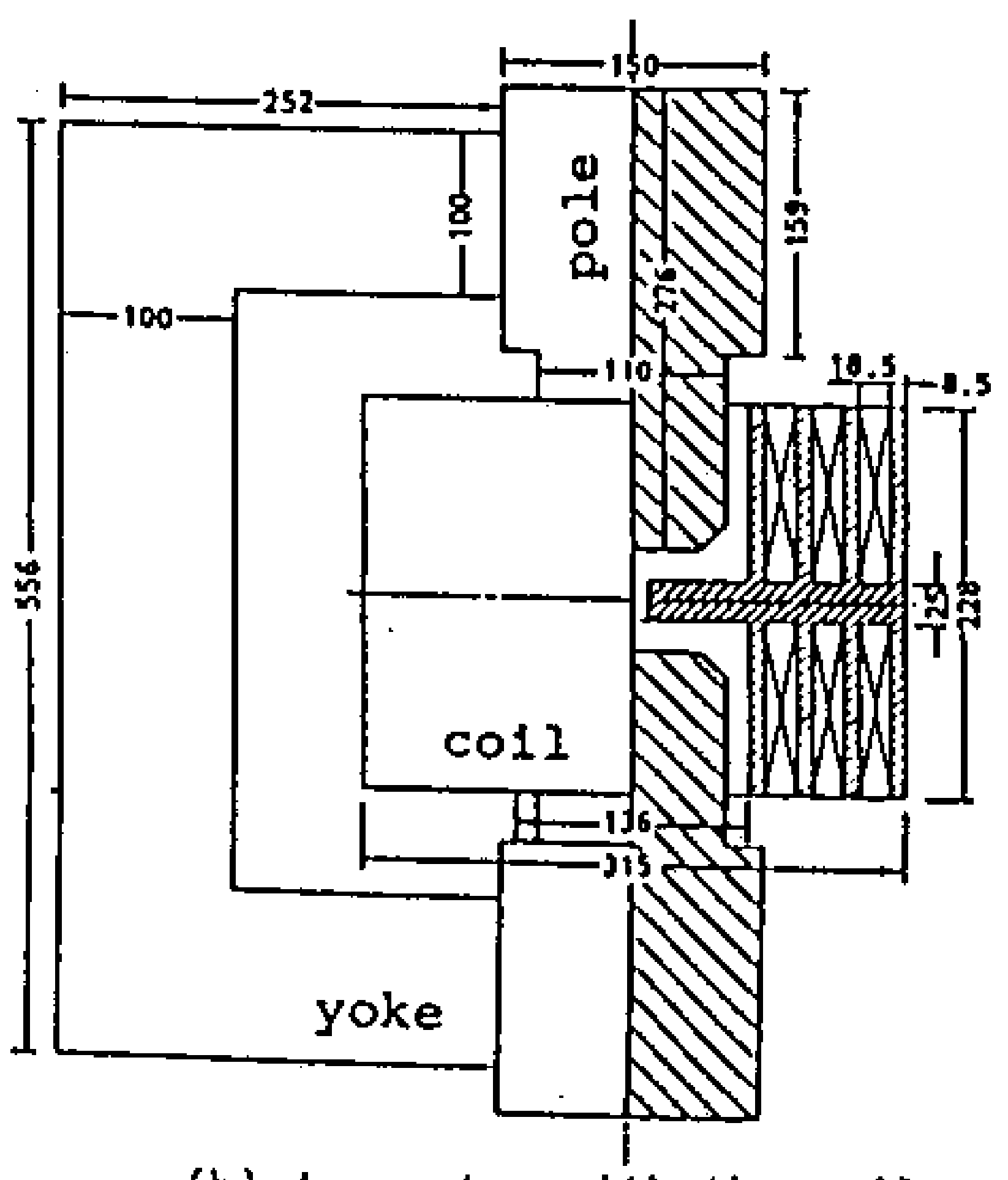

(b) Apparatus with the coll

FIg.2 Multilayer eddy-current type generator 
them is the disc type coll shown in Fig.5. This coil is made of both the disc coll for the magnetizing current where a slit is set up in the radial direction, and the conductor disc plate where a fanshaped silt is deslgned for eddy currents. These two types of the disc coll and plate are piled up alternately as shown in Fig.5(a). These disc colls are connected at the slit as a series magnetizing coll. The disc plates with Insulators are Inserted between disc colls. Figure $5(b)$ shows the flow of the magnetizing current in the disc coll and the eddy current in the disc plate when an ac current is applied.

In our small experlmental model for testing, the device is made of copper. The outer dlameter of the disc coll is $200 \mathrm{~mm}$ and the width is $30 \mathrm{~mm}$. The outer diameter of the disc plate is the same as that of the disc coll.

\section{Spiral-type coil}

In the other device, the splral coll in Fig. 6 is used for magnetlzing current coll instead of the disc coll. It has a structure simllar to the disc type coll.

Comparing with the former, the splral-type coll is more sultable for hlgh voltage and small current. It may be used in the low frequency range. The former can be used for low voltage and high current.

\section{CILARACTERISTICS}

Te have conducted experiments with a test model of the disc-type laminated coll. Figure 7 shows the characteristics of magnetic flux density in the hole ith the number of colls. The condition of measurements is that the applled voltage for one magnetizing coll is constant. The applied voltage is $40 \mathrm{mV}$ at each coll in Fig.7. The flux density increases linearly with applied voltage. He can observe the concentrating effect of magnetlc plux when the disc plate is put in.

Flgure 8 shows the characterlstics of magnetic flux density with the thickness of a disc plate when

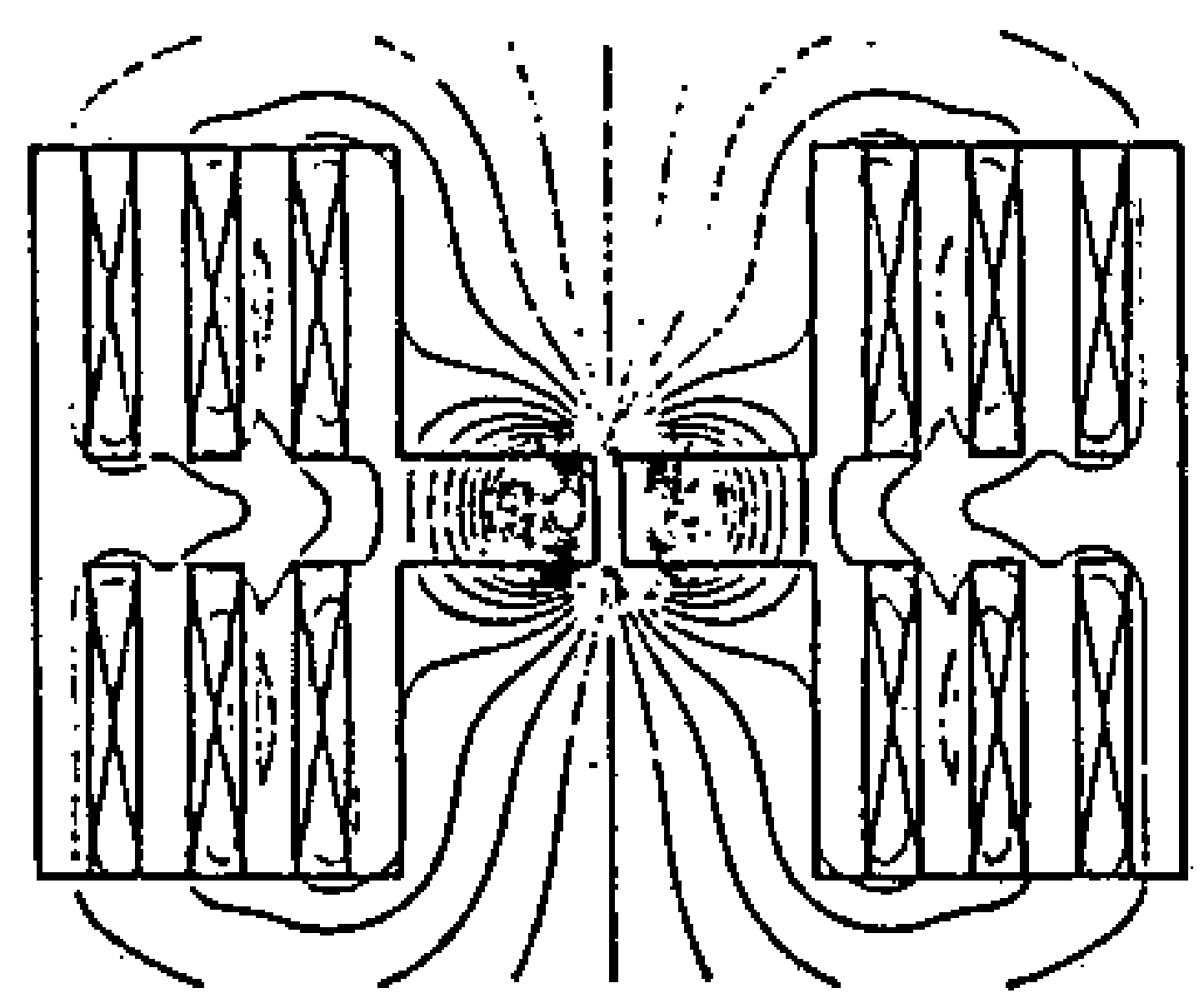

Fig.3.Flux distribution obtained by the FEM

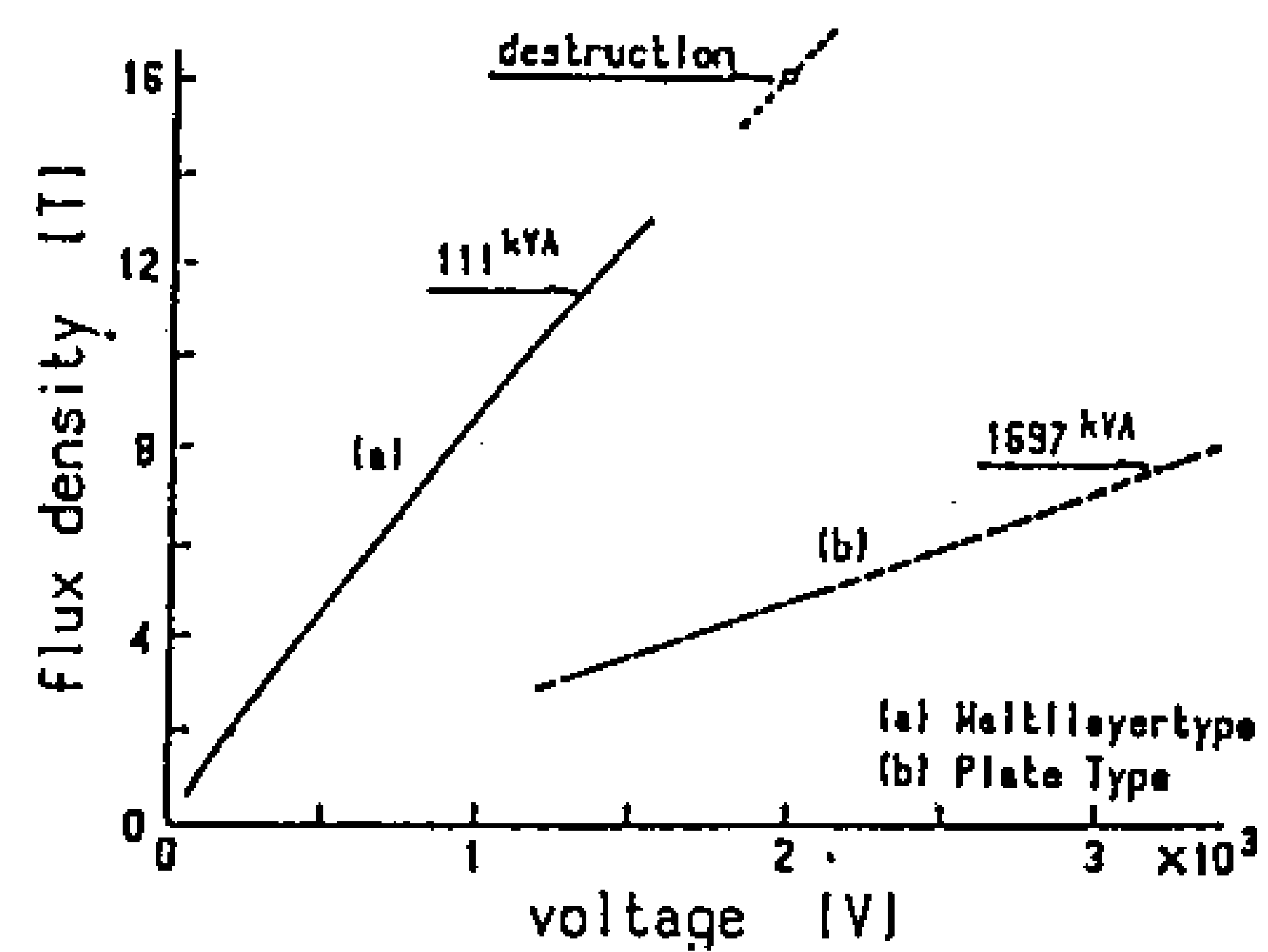

F1g.4 Characterlstics of the multilayer-type generator the applied voltage of one coll is kept constant. The maximum value is at $5 \mathrm{~mm}$. He consider that this value corresponds to the skin depth of the disc plate.

\section{ANALYSIS OF TIIE LAMUMATED COLL BY FEM}

In order to analyze the flux distribution in the laminated coll, we consider the model as shown in Fig.9. The colls and plates are axisymmetric and the eddy currents flow inside the individual conductors. The technique of the FEM applied to this problen is reported in [3]. In this problem, eddy currents flow in both the magnetizing. colls and the plates. Therefore, the following conditions must be satisfled as follows.

In the magnetizing coil:

$$
\int_{S}\left(J_{1 n}+J_{0}\right) d S=I_{\mathrm{in}}
$$

In the conducting plate:

$$
\int_{s} d S=0
$$

where $J_{1 n}, I_{1 n}$ and $J_{e}$ are the magnetizing current

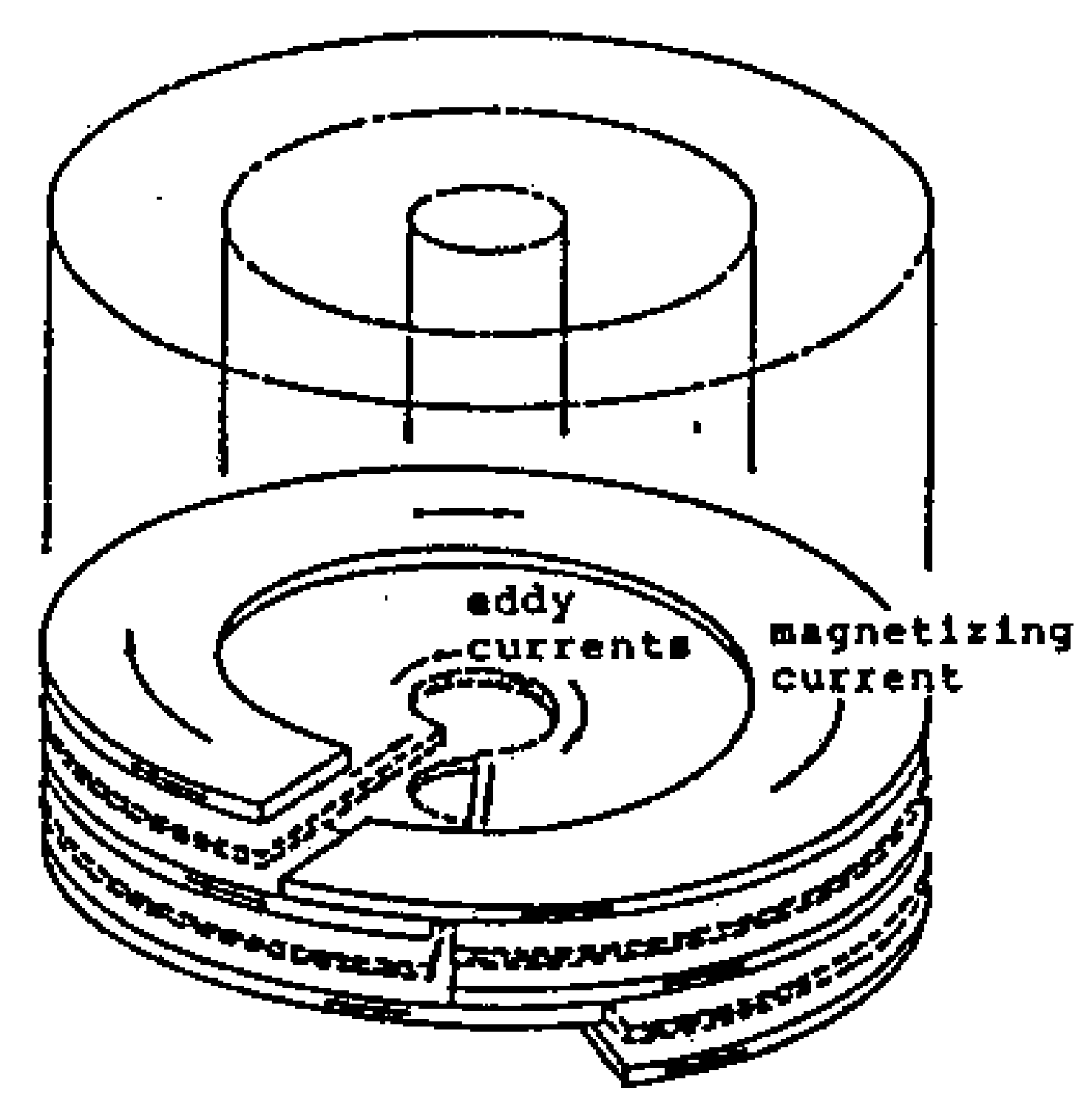

(a) Structure

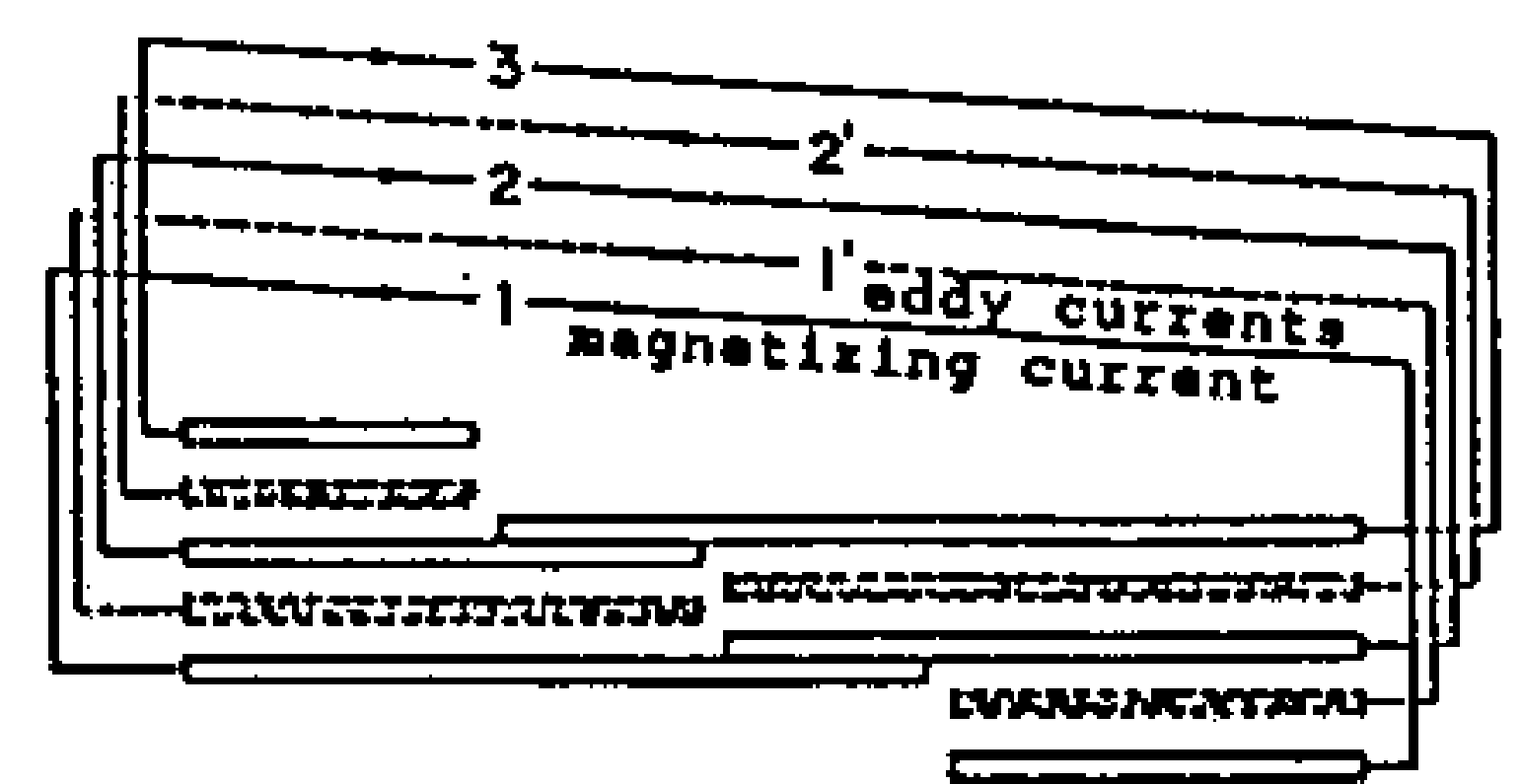

(b) Connection of the colls

Fig.5 Disc-type laminated coll

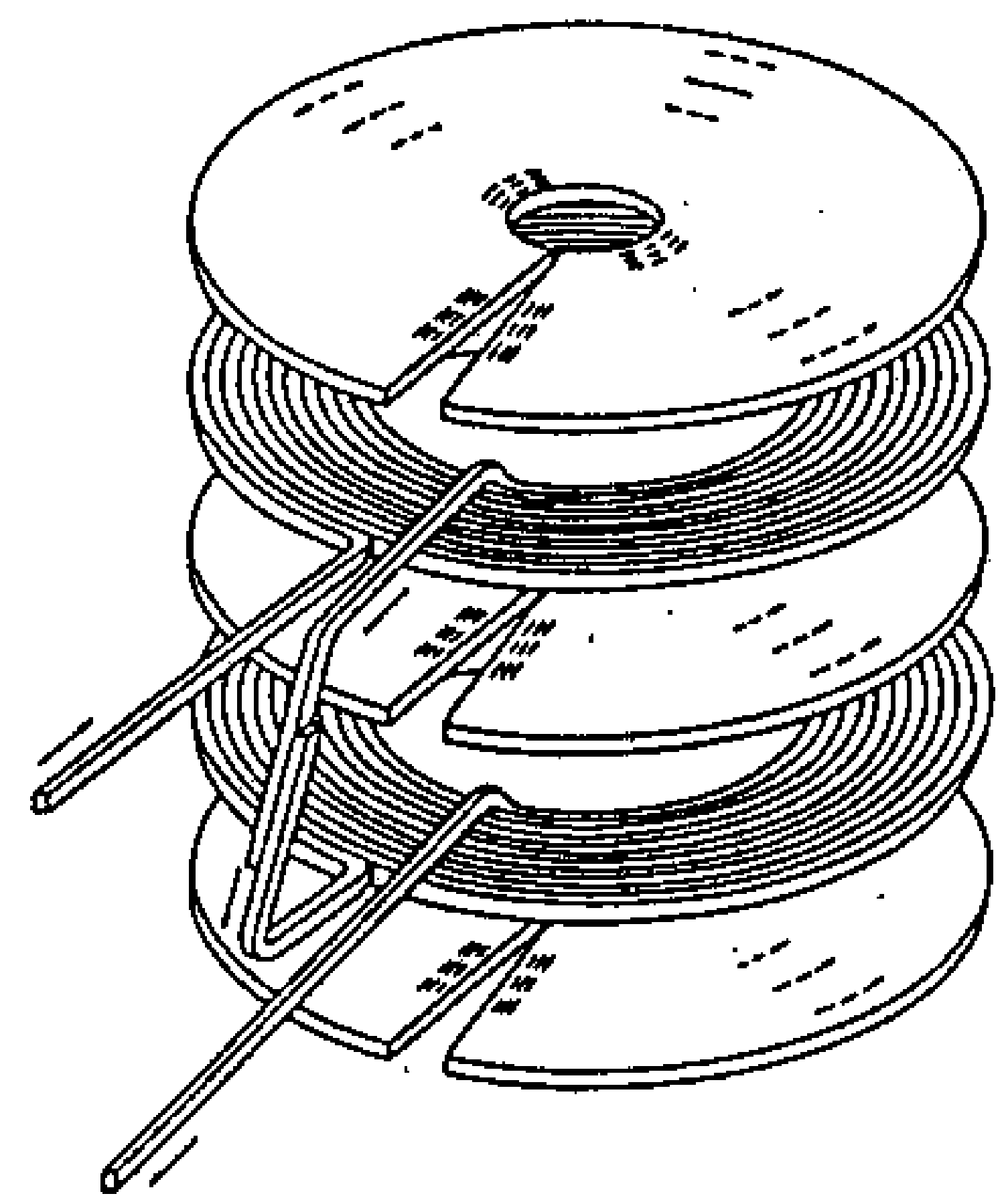

Flg.6 Splral-type laminated coll 
density, the magnetizing current and the eddy-current density respectively. The integration is made in the cross section $S$ of the coll and the plate.

Figure 10 shows the flux distribution in the disc-type coll. When the magnetizing current density has $J_{1 n} s$ inwt, the flux density has the maximum value at the phase w $t=2 \pi / 3$ because of eddy currents.

Figure 11 shows the relation between the flux density in the hole and the number of colls. This result agrees with that in Fig, 7 .

\section{CONCLUSION}

The concentration of a magnetlc flux by using laminated colls is discussed. These colls are sulted to generating an ac high magnetic fleld and the structures of the colls are simpler than the former in construction. It may be used for obtaining an ac high magnetic fleld. It can also be applied to the induction electromagnetic pump.

\section{REFERENCES}

(1) K.Bessho, S.Yamada, M.Kooto,T.Minam1 tan1. N. Nakano, M.Masahash1; "AC. h1gh magnetic fleld generator using multilayer eddy-current type coll". Proc. of Sof t Magnetic Materlals 8, 5-26, (1987).

(2) T.Yoshimoto, K.Bessho, S.Yamada:"Three dimensional FEM analys Is of a cylinder-type flux concentration apparatus". IEEE Trans. Magn., Vol.MAG-24, No.6. (1988).

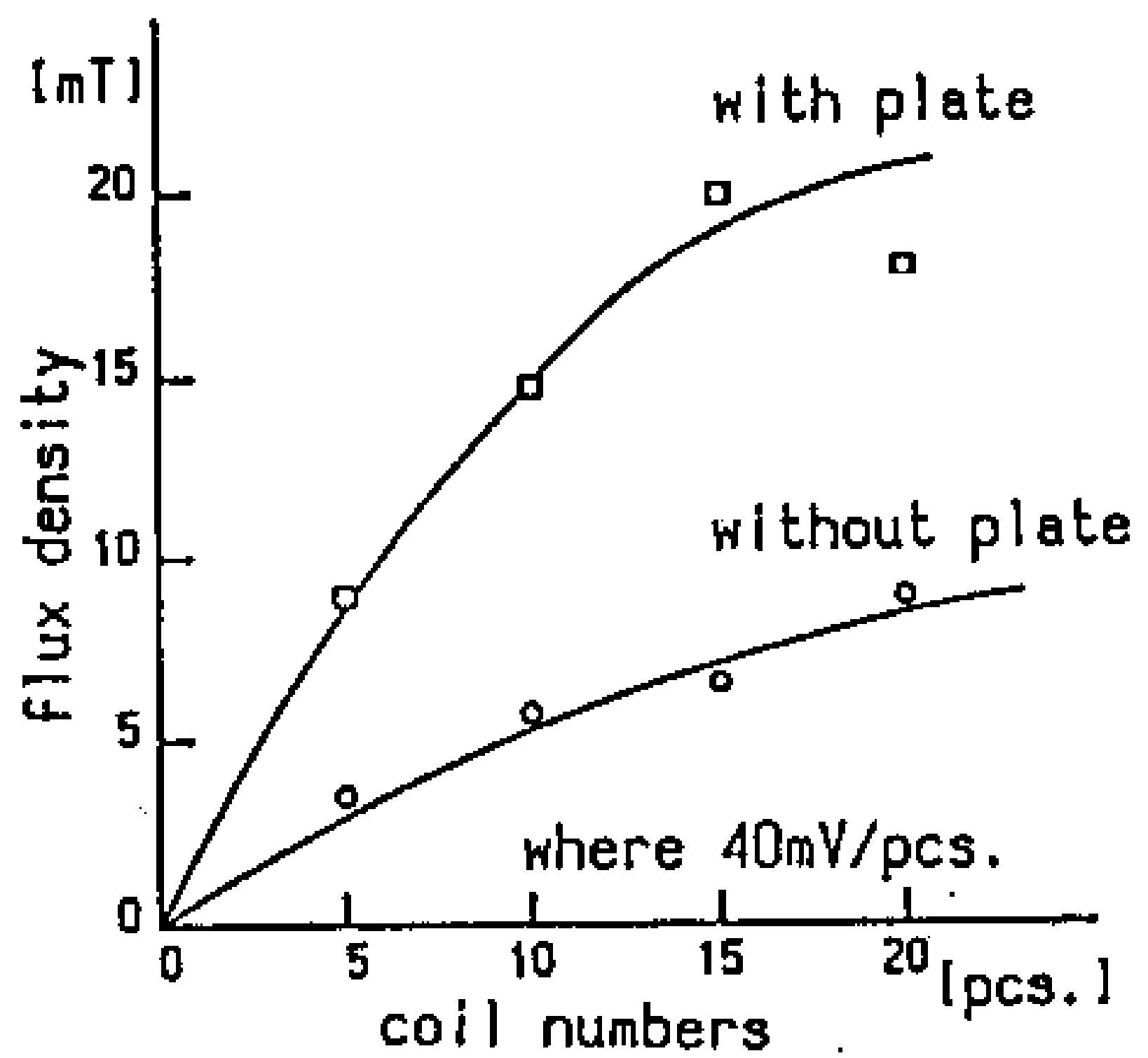

Fig.7 Relation between the number of colls and flux density in the hole

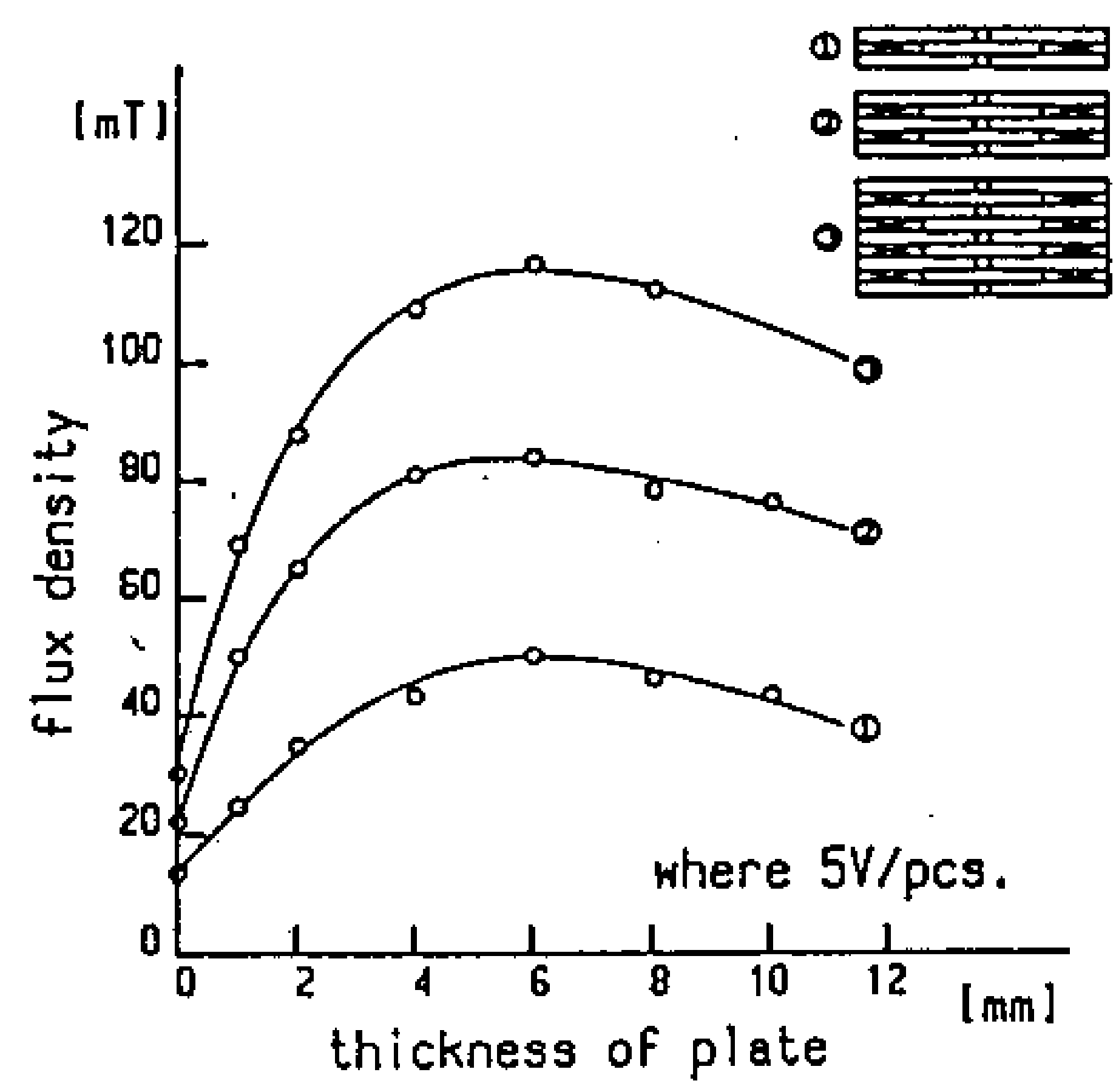

Flg.8 Relation betricen thlckness of conductor and flux density
(3) K. Bessho, S.Yamada, M.Kooto, M.Masahash1, M. Nakano, : "Characteristlcs of multilayer eddy-current type ac magnetic coll with cooling system", J. Appl. Phys. Vol.64, No.10-8, (1988).

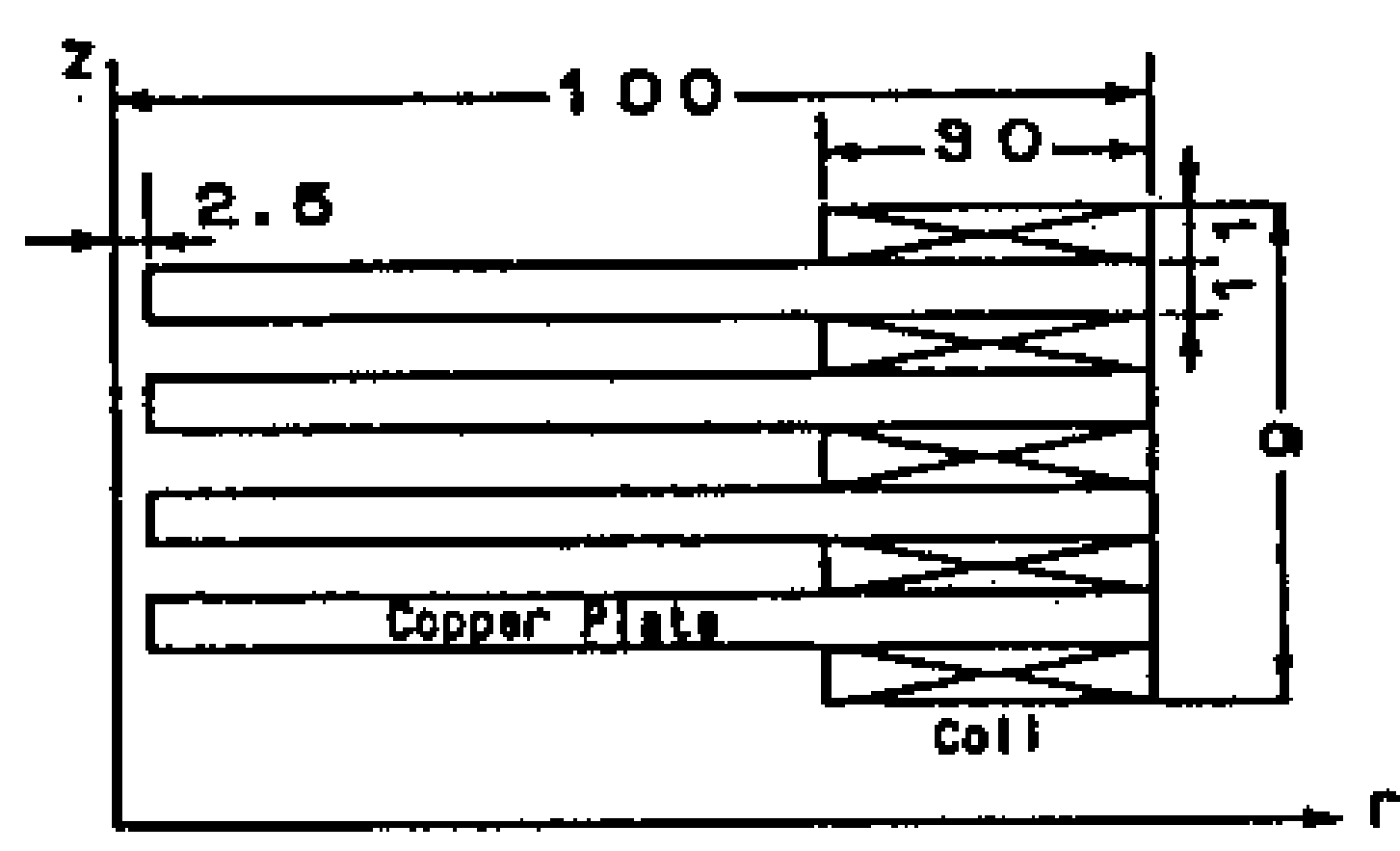

Fig.9 Model of the laminated coll

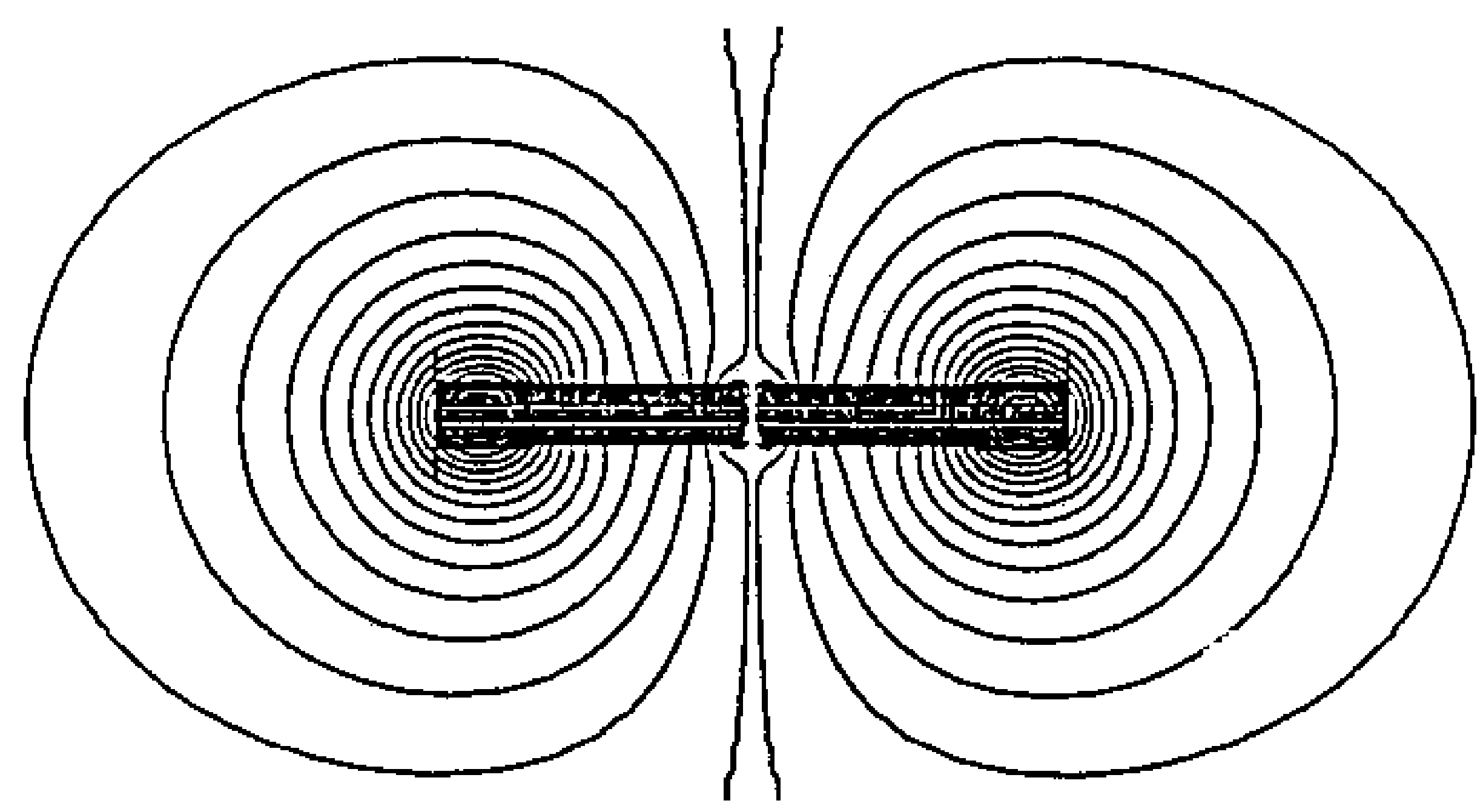

(a) $\omega t=0$

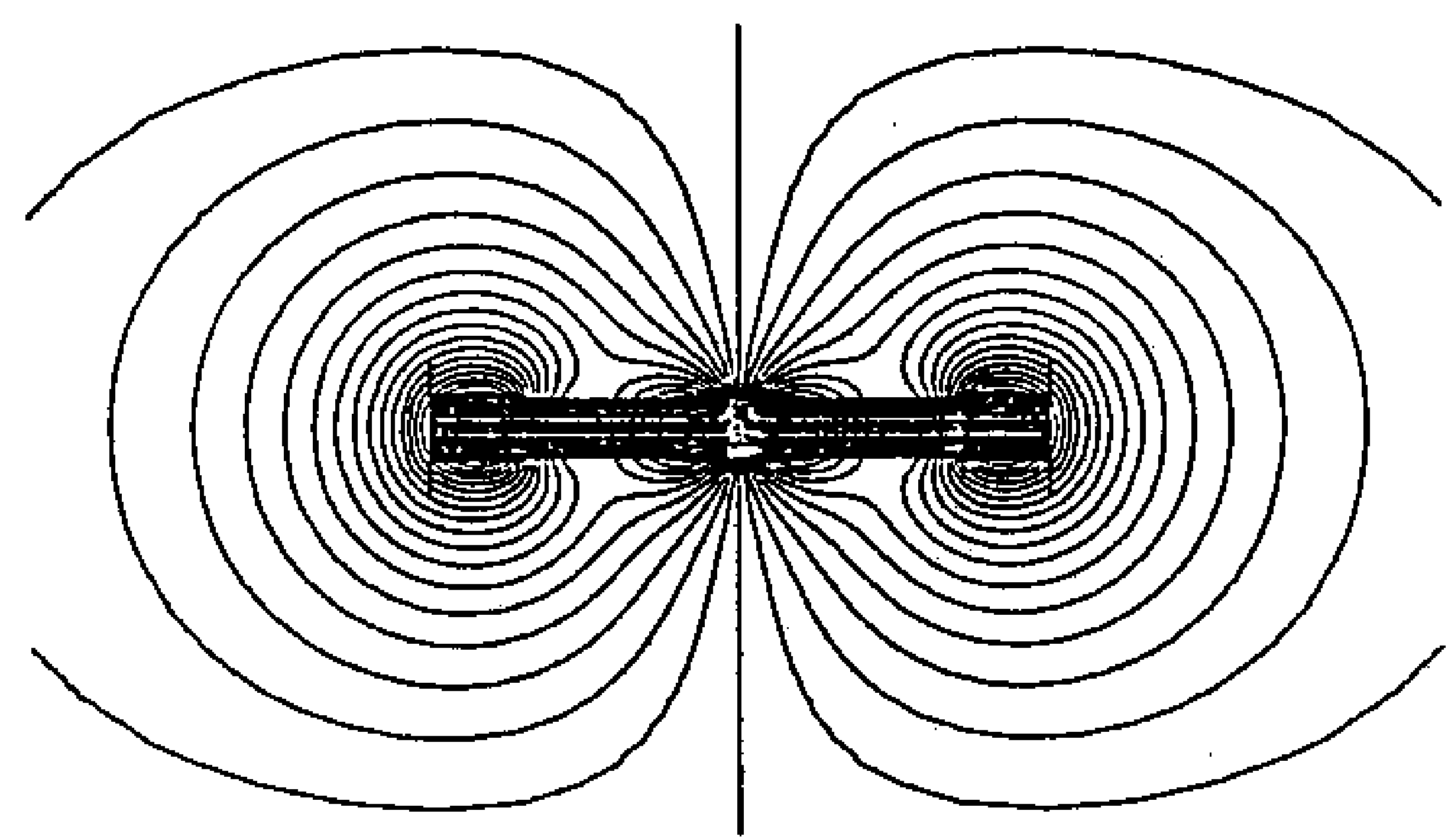

(b) $\omega t=2 \pi / 3$

F1g.10 Flux distribution calculated by the FEM

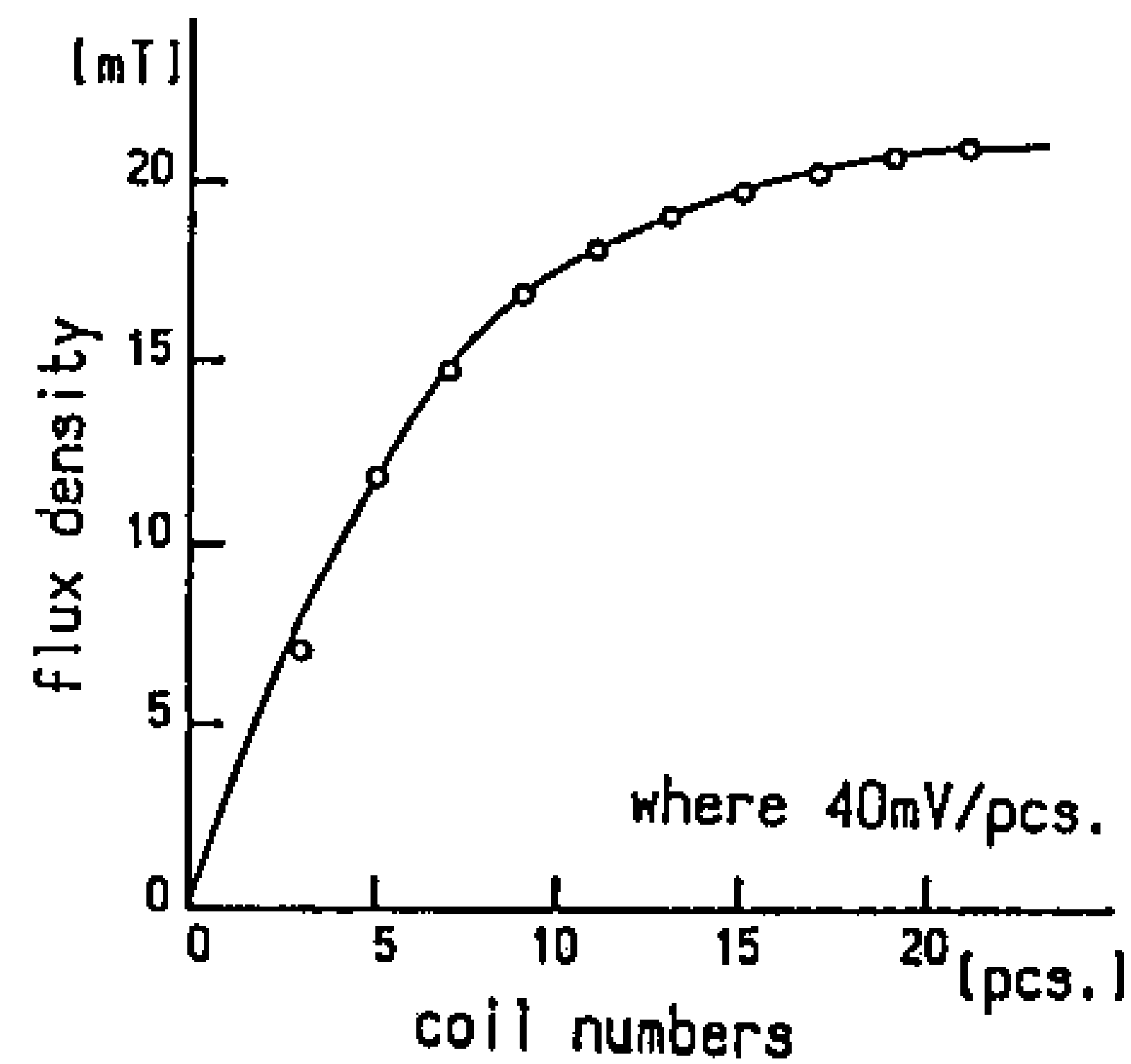

Fig.11 Relation between the number of colls and flux density by the FEM 